\title{
Burnout and Resilience among Frontline Nurses during COVID-19 Pandemic: A Cross-sectional Study in the Emergency Department of a Tertiary Care Center, North India
}

\author{
Sinu Jose ${ }^{1}$, Manju Dhandapani ${ }^{2}$, Maneesha C Cyriac ${ }^{3}$
}

\begin{abstract}
Background: The COVID-19 pandemic had a massive impact on healthcare systems, increasing the risks of psychological distress in health professionals. Burnout is a prolonged response to chronic emotional and interpersonal stressors on the job and is defined by the three dimensions of emotional exhaustion, cynicism, and personal inefficacy.

Methodology: A cross-sectional descriptive design was used to assess the burnout and resilience among frontline nurses in the emergency department of a tertiary care center in North India during COVID-19 pandemic. The sample consisted of 120 frontline nurses working in the emergency department, selected by a simple random sampling method. Data were collected using the Maslach burnout inventory-general survey and the Connor-Davidson Resilience Scale.

Results: The nurses in the emergency during pandemic experienced a moderate-to-severe level of burnout in emotional exhaustion (29.13 \pm $10.30)$ and depersonalization (12.90 \pm 4.67$)$ but mild-to-moderate level of burnout in reduced personal accomplishment (37.68 \pm 5.17$)$ and showed a moderate to a high level of resilience $(77.77 \pm 12.41)$. The two metrics of burnout viz., emotional exhaustion and personal inefficacy had a significantly negative correlation with resilience among the frontline nurses in the emergency $(r=0.25, p<0.05$ and $r=0.31, p<0.01$, respectively). A significant negative correlation has been identified between burnout and resilience that informs the role of resilience in alleviating burnout during this pandemic.

Conclusion: Effective interventions for improving resilience are needed to relieve nurses'burnout and workplace stressors. Also, the administration should ensure a healthy workplace and adopt a positive attitude and harmonious relationship with the frontline workers in the mitigation of the pandemic.

Keywords: Burnout, COVID-19 pandemic, Emergency nurses, Emotional exhaustion, Frontline nurses, Hardiness, Optimism, Resilience.

Indian Journal of Critical Care Medicine (2020): 10.5005/jp-journals-10071-23667
\end{abstract}

\section{INTRODUCTION}

In March 2020, due to the global spread of the disease, COVID-19 was declared as a pandemic, causing widespread concern " In India, nearly 79,000 new cases added on August 29, 2020, the highest single-day surge recorded in any country so far with 3.5 million total cases marks an unprecedented spike in pandemic over the past several months". " "More than 87,000 health workers have been infected with COVID-19 accounting for about $74 \%$ of the case burden and $86 \%$ of death of COVID-19 in India". ${ }^{3}$ So, it is clear that healthcare workers are among the high-risk group to be infected by COVID-19. Thus, COVID-19 pandemic created a public health crisis in India, which had a tremendous influence on the personal and professional lives of healthcare professionals. The nurses in the frontline are working non-stop to contain the outbreak, so we should be concerned about the health of them, both physically and mentally not to be burned out.

According to $\mathrm{WHO}$, burnout is recognized as an extended response to workplace stress, which is not managed effectively. In a national survey conducted among nurses in the USA in April 2019, $15.6 \%$ of nurses reported a feeling of burnout, with a higher risk among nurses in the emergency department. ${ }^{4}$ Besides workload, dealing with critically ill patients and emotionally overloaded relatives is a highly challenging job for nurses working in the emergency department during a pandemic.

Infectious diseases, pandemics, especially respiratory, are the most psychologically damaging because they are so deadly, contagious, and long-lasting; the coronavirus pandemic is one with
${ }^{1}$ Department of Nursing, Postgraduate Institute of Medical Education and Research, Chandigarh, India

${ }^{2}$ National Institute of Nursing Education, Postgraduate Institute of Medical Education and Research, Chandigarh, India

${ }^{3}$ Bel-Air College of Nursing, Panchgani, Maharashtra, India

Corresponding Author: Sinu Jose, Department of Nursing, Postgraduate Institute of Medical Education and Research, Chandigarh, India, Phone: +91 8146061896, e-mail: sinujosekudilil87@gmail.com

How to cite this article: Jose S, Dhandapani M, Cyriac MC. Burnout and Resilience among Frontline Nurses during COVID-19 Pandemic: A Cross-sectional Study in the Emergency Department of a Tertiary Care Center, North India. Indian J Crit Care Med 2020;24(11):1081-1088.

Source of support: Nil

Conflict of interest: None

such combinations. The COVID-19 outbreak has resulted in many mental health outcomes depending on the individual's strengths and weaknesses, the major stressors added to the nurses during the pandemic are the physical strain of personal protective equipments (PPEs) (dehydration, heat, and exhaustion) and physical isolation (cannot touch others), constant vigilance regarding infection control procedures, fears about infection, and inner conflicts about competing needs and demands. Healthcare workers in India are mostly affected by internal and external stigma related to the COVID-19 virus and its impacts. ${ }^{5-7}$ 
One of the most important steps to prevent burnout is the early identification of the sources of stressors and the modification of individual personality traits and psychological functions. Recently, psychological resilience, a concept of personality traits having protective effects against burnout, is identified. Resilience is a person's adaptation to important stressful sources such as trauma, threat, tragedy, familial and relationship problems, workplace, and financial issues. ${ }^{8,9}$ Resilience is important for nurses, who encounter many risk factors in their day-to-day work life and have to provide standard care to the patients.

With an increase in resilience, the nurses can cope with the negative conditions. Better adaptation and achievements are increased, and thereby they experience a better quality of working experience, which minimizes the burnout among them.

This study aims to determine the burnout and resilience and its associated factors among the frontline nurses who provide direct care for the patients in the emergency department of a tertiary care center in North India.

\section{Materials and Methods \\ Research Design and Participants}

A descriptive cross-sectional research design was employed to assess the burnout and resilience of the frontline nurses in the emergency department of a tertiary care center in North India. The sample consisted of 120 frontline nurses selected by simple random sampling from various emergency care areas; medicine, surgery, and trauma outpatient departments of a tertiary care center in North India.

\section{Tools and Techniques}

Appropriate standardized tools were selected after a thorough literature search with the consensus of all the investigators. The self-report questionnaire chosen to assess burnout and resilience is standardized tools with high validity and reliability.

\section{Maslach Burnout Inventory}

Human Services Survey for Health Personnel (MBI-HSS) ${ }^{10}$ was used to assess the burnout among the nurses. It consisted of 22 items, under three different dimensions viz emotional exhaustion, depersonalization, and personal accomplishments. The emotional exhaustion domain assessed by a 9-item scale identifies the feeling of being emotionally overextended and over-exhausted by one's work. Depersonalization domain (5 items) in the tool measures an unfeeling and impersonal response toward the recipient of one's service, care, treatment, or instruction. There are eight items in the personal accomplishment domain, which assesses the feelings of competence and achievements in one's work with people. The subjects were asked to respond to a 6-point Likert scale for measuring each item freely. Based on the obtained score, burnout in different dimensions was categorized as follows (Table 1).

The higher the score for emotional exhaustion and depersonalization, the severe is the burnout, while a lower score of personal accomplishment indicates more severe burnout. In Table 1: MBI-human services survey score classification

\begin{tabular}{llll}
\hline & \multicolumn{3}{c}{ Moderate } \\
& Low burnout & burnout & High burnout \\
\hline Emotional exhaustion & $0-16$ & $17-26$ & $>27$ \\
Depersonalization & $0-6$ & $7-12$ & $>13$ \\
Personal accomplishment & $>39$ & $32-38$ & $0-31$ \\
\hline
\end{tabular}

this study, Cronbach alpha coefficients for emotional exhaustion, depersonalization, and personal accomplishment were $0.88,0.83$, and 0.82 , respectively.

\section{Connor-Davidson Resilience Scale-25 (CD-RISC)}

A 25 -item 5 points Likert scale was used to measure the resilience of frontline nurses in the emergency department during the COVID-19 pandemic. This tool measures the ability to cope with stress and adversity with four aspects of resilience: hardiness (8 items), optimism (6 items), resourcefulness/self-efficacy (8 items), and meaningfulness/purpose ( 3 items). The participants had to rate the items on how he felt for the past month; the range of responses was; not true at all (0), rarely true (1), sometimes true (3), and true nearly all of the time (4). Total scores ranged from 0 to 100 with higher scores reflected greater resilience. ${ }^{11}$ The Cronbach alpha coefficient scores for the scale in this study was 0.89 .

\section{Data Collection Procedure}

Ethical clearance was obtained from the institutional ethics committee. The participants were informed about the purpose of the study, and informed consent was taken before the data collection. A web-based Google form survey was sent on the internet through any social media of selected participants. Participation in the study was fully voluntary and non-commercial. We could get a $100 \%$ response rate from the participants with reminders, and the mandatory items were highlighted in the tools. The survey never displayed the second time once the user had filled it in and protected from editing after submission. Data were collected during August 2020, after getting permission from the concerned authorities. The data collected were stored in Google drive and protected by username and password.

\section{Results}

Data were collected from 120 frontline nurses working in the emergency departments and analyzed with SPSS version 22.0. An analysis of descriptive statistics was conducted to illustrate the demographic characteristics, level of burnout, and resilience of the participants. Correlation between burnout and resilience was identified by using the Pearson correlation test and the Chisquare test was used to find out the association between selected demographic variables and study variables.

\section{Sociodemographic Characteristics of Participants}

Of the 120 frontline nurses participated, the age ranged from 23 to 45 years with a mean age of $29(S D=4.44)$, women comprised $73.3 \%$ of the participants; married nurses' accounts for $45 \%$ and $54.2 \%$ were single, and $32 \%$ had children and $1.6 \%$ were pregnant at the time of data collection. Participating nurses had a mean of $5.6(S D=4)$ years of experience in the emergency department and most held a basic or post-basic nursing degree (88\%) from various universities in India.

Table 2 depicts that the majority of the study participants were $<30$ years old. Only 11 (9.2\%) participants had $>10$ years' experience in the emergency department. About $91 \%$ of participants were living with their families or in groups. Nearly $72 \%$ of subjects were exposed to positive cases unexpectedly without any protective gear. When $80 \%$ of the subjects were confident in self-protection against COVID-19 infection, $86 \%$ feared infecting family members. More than half (56\%) of participants felt that their workplace is safe against the COVID-19 infection spread. 
Table 2: Distribution of frontline nurses in the emergency department based on sociodemographic data and perception related to COVID-19 $(n=120)$

\begin{tabular}{|c|c|}
\hline Variables & $f(\%)$ \\
\hline \multicolumn{2}{|l|}{ Age groups (years) } \\
\hline$<30$ & $78(65)$ \\
\hline $31-40$ & $38(31.7)$ \\
\hline$>41$ & $4(3.3)$ \\
\hline \multicolumn{2}{|l|}{ Gender } \\
\hline Female & $88(73.3)$ \\
\hline Male & $32(26.7)$ \\
\hline \multicolumn{2}{|l|}{ Education } \\
\hline Diploma in nursing & $10(8.3)$ \\
\hline Basic/post-basic degree in nursing & $106(88.3)$ \\
\hline Postgraduation in nursing & $4(3.4)$ \\
\hline \multicolumn{2}{|l|}{ Year of experience in emergency } \\
\hline $1-5$ & $72(60)$ \\
\hline $6-10$ & $37(30.8)$ \\
\hline$>11$ & $11(9.2)$ \\
\hline \multicolumn{2}{|l|}{ Marital status } \\
\hline Unmarried & $65(54.2)$ \\
\hline Married & $54(45)$ \\
\hline Separated/divorced & $1(0.8)$ \\
\hline \multicolumn{2}{|l|}{ Number of members in the household } \\
\hline Alone & $11(9.2)$ \\
\hline $2-5$ & $91(75.8)$ \\
\hline$>6$ & $18(15)$ \\
\hline \multicolumn{2}{|l|}{ Having children } \\
\hline No & $80(66.7)$ \\
\hline Yes & $38(31.7)$ \\
\hline Pregnant & $2(1.6)$ \\
\hline \multicolumn{2}{|c|}{ Contact with COVID-19 confirmed patients without protection } \\
\hline Yes & $86(71.7)$ \\
\hline No & $34(28.3)$ \\
\hline \multicolumn{2}{|l|}{ Confident in self-protection } \\
\hline Yes & $80(66.7)$ \\
\hline No & $40(33.3)$ \\
\hline \multicolumn{2}{|c|}{ Perception of safety against COVID-19 in working place } \\
\hline Very safe & $17(15.7)$ \\
\hline Safe & $44(40.7)$ \\
\hline Somewhat safe & $33(30.6)$ \\
\hline Unsafe & $3(2.8)$ \\
\hline Very unsafe & $11(10.2)$ \\
\hline \multicolumn{2}{|l|}{ Fear of infecting family members } \\
\hline Yes & $103(85.8)$ \\
\hline No & $17(14.2)$ \\
\hline
\end{tabular}

\section{Burnout and Resilience among Frontline Nurses in the Emergency}

The total mean percentage score for emotional exhaustion, depersonalization, and personal accomplishment was $54 \%(29.13$ $\pm 10.30 / 54), 43 \%(12.9 \pm 4.67 / 30)$, and $78.5 \%(37.68 \pm 5.7 / 48)$, respectively.

Figure 1 shows a mean score for the frontline nurses who had high-level emotional exhaustion is remarkably higher than those

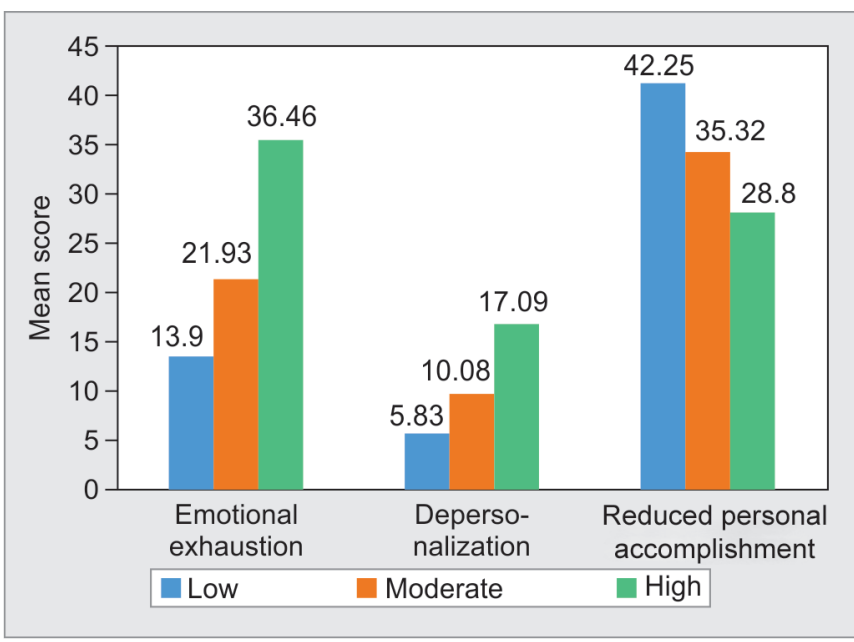

Fig. 1: Mean scores of the burnout among frontline nurses during COVID-19 pandemic

Table 3: Burnout among frontline nurses in the emergency during COVID-19 pandemic $(n=120)$

\begin{tabular}{ll}
\hline Burnout dimensions & Mean $\pm S D, f(\%)$ \\
\hline Emotional exhaustion & $29.13 \pm 10.30$ \\
Low (0-16) & $10(8.3 \%)$ \\
Moderate (17-26) & $45(37.5 \%)$ \\
High (27-54) & $65(54.2 \%)$ \\
Depersonalization & $12.90 \pm 4.67$ \\
Low (0-6) & $6(5 \%)$ \\
Moderate (7-12) & $62(51.7 \%)$ \\
High (13-30) & $52(43.3 \%)$ \\
Reduced personal accomplishment & $37.68 \pm 5.17$ \\
Low (>39) & $55(45.8 \%)$ \\
Moderate (32-38) & $50(41.7 \%)$ \\
High (0-31) & $15(12.5 \%)$ \\
\hline
\end{tabular}

with mild-to-moderate emotional exhaustion. In contrast, the mean score for personal accomplishment among the nurses who had reduced personal efficiency is only 28.8 .

Table 3 shows three dimensions of burnout among nurses in the emergency department in North India. More than half of the nurses (54\%) reported high and $37 \%$ reported a moderate level of burnout in emotional exhaustion. About $52 \%$ of the participants expressed a moderate level of depersonalization, whereas only $12.5 \%$ were had a high level of reduced personal accomplishment.

The total score in CD-RISC-25 ranged from 43 to 97 with a mean score of 77.77 ( $S D=12.41$ ) suggesting that generally, nurses in the emergency department had a moderate to a high level of resilience.

Figure 2 shows that $47.5 \%$ of the participants had a high level of resilience, but only $15.8 \%$ of frontline nurses expressed low resilience.

Table 4 depicts the mean scores for the four aspects of resilience, hardiness, self-efficacy, optimism, and meaningfulness/ purpose were 22.80 (SD 3.80), 24.15 (SD 4.75), 18.33 (SD 3.28), and 12.50 (SD 2.45), respectively, suggesting that generally, nurses had a moderate to a high level of resilience. $47.5 \%$ of the frontline nurses expressed a high and moderate level of hardiness, whereas $53.3 \%$ of participants had a moderate level of self-efficacy and $45.8 \%$ expressed a moderate level of optimism. 


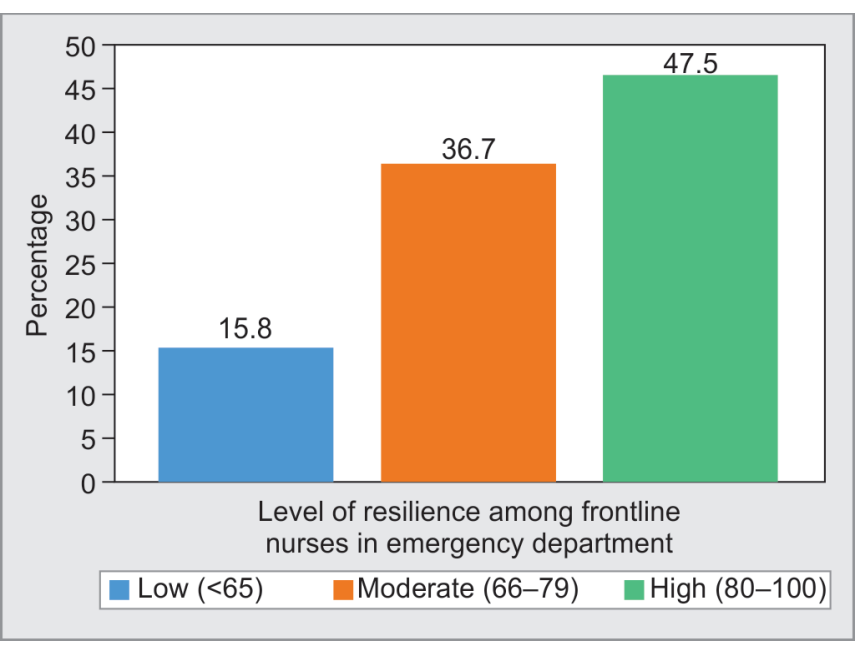

Fig. 2: Resilience among frontline nurses in the emergency department during the COVID-19 pandemic

Table 4: Mean resilience scores among frontline nurses in the emergency department during COVID-19 pandemic $(n=120)$

\begin{tabular}{ll}
\hline Aspects of resilience & Mean \pm SD, $f(\%)$ \\
\hline Hardiness & $22.80 \pm 3.80$ \\
High $(24-28)$ & $57(47.5 \%)$ \\
Moderate (17-23) & $57(47.5 \%)$ \\
Low $(<16)$ & $6(5 \%)$ \\
Self-efficacy & $24.15 \pm 4.75$ \\
High $(26-32)$ & $51(42.5 \%)$ \\
Moderate $(16-25)$ & $64(53.3 \%)$ \\
Low $(<15)$ & $5(4.2 \%)$ \\
Meaningfulness/purpose & $12.50 \pm 2.45$ \\
High $(11-16)$ & $94(78.3 \%)$ \\
Low $(<10)$ & $26(21.7 \%)$ \\
Optimism & $18.33 \pm 3.28$ \\
High $(21-24)$ & $37(30.8 \%)$ \\
Medium $(16-20)$ & $55(45.8 \%)$ \\
Low $(<21)$ & $28(23.4 \%)$ \\
\hline
\end{tabular}

\section{Correlation between Burnout and Resilience}

The total score of resilience showed a significant negative relationship with emotional exhaustion and reduced professional efficacy.

Table 5 shows that emotional exhaustion and reduced personal accomplishments significantly negatively correlated with total resilience $(r=0.25, p<0.05$ and $r=0.31, p<0.01$, respectively), but there is no significant relation between depersonalization and resilience. So, we can conclude that an increase in resilience among the nurses will help in mitigating burnout symptoms; however, the correlations were weak, with all of the values for the correlation coefficients between 0.2 and 0.4 .

\section{Association between Burnout and Resilience of Nurses in the Emergency Department with Selected Demographic Variables}

Table 6 shows that emotional exhaustion was reported by significantly more among nurses who had a fear of infecting family
Table 5: Correlation between burnout and resilience among frontline nurses working in the emergency department $(n=120)$

\begin{tabular}{llll}
\hline & $\begin{array}{l}\text { Emotional } \\
\text { exhaustion }\end{array}$ & $\begin{array}{l}\text { Depersonaliza- } \\
\text { tion }\end{array}$ & $\begin{array}{l}\text { Reduced personal } \\
\text { accomplishment }\end{array}$ \\
\hline $\begin{array}{l}\text { Resilience } \\
\text { score }\end{array}$ & $-0.252^{*}$ & -0.069 & $-0.313^{* *}$ \\
\hline
\end{tabular}

*Significant at 0.05

**Significant at 0.01

members $(77.5 \%)$, had confidence in self-protection (56.6\%), and had felt poor safety in the workplace (46\%).

Table 7 shows that moderate to a high level of depersonalization was reported by significantly more (62\%) of the frontline nurses in emergency below 30 years $\left(\chi^{2}=9.47, p<0.05\right)$.

Table 8 shows that $33.33 \%$ of female participants in the study had a higher level of personal accomplishment $\left(\chi^{2}=6.84, p<0.05\right)$ and those frontline nurses who are living with family or in groups (41\%) had reported a higher level of personal accomplishment $\left(\chi^{2}\right.$ $=9.35, p<0.05$ ). So, the personal accomplishment among frontline nurses in the emergency was found to have a significant association with the gender and number of members in the household.

Table 9 shows that there is no significant association between the resilience of frontline nurses in emergency and sociodemographic variables, but the nurses who were exposed to COVID-19 patients (40\%) reported high resilience $\left(\chi^{2}=9.21, p<\right.$ 0.01 ) and also a high level of resilience was reported by the nurses (35\%) who had perceived the workplace as unsafe $\left(\chi^{2}=5.130\right.$, $p<0.05)$.

\section{Discussion}

Battling COVID-19 on the frontline makes nurses vulnerable to much psychological distress. Hence, the present study focused on the mental health impacts of the COVID-19 pandemic on frontline nurses in the emergency department of a tertiary care center in North India. Previous studies conducted among healthcare providers revealed that nurses are at more risk of burnout than other healthcare providers because they are working in close contact with affected patients for longer hours. ${ }^{12,13}$

The present study identified that $86 \%$ of the frontline nurses in emergency feared transmitting COVID-19 to family members, even they comply with infection prevention practices. Similar findings were identified in a study conducted among dentists, where subjects were afraid of being infected by their patients or coworkers. ${ }^{14}$ In the general population, they were terrified of getting infected by other people in the community during a pandemic. ${ }^{15}$ Since the mode of transmission of the infection is established to be droplet and aerosols, it enhanced the likelihood of nurses getting infected and spreading to family. The majority of the subjects perceived inadequate workplace safety against COVID-19 in the emergency department. About $76 \%$ of the subjects without proper protective equipment were exposed to COVID-19 patients without knowing their positive status.

In general, the outbreak of an emerging disease contributes to a general atmosphere of fear that needs to be psychologically studied through comprehensive research activity to understand its possible negative impacts on individuals' mental health and productivity, to mitigate such impacts on the HCWs, in particular, who are in the frontline of counteracting the disease. 
Burnout and Resilience among Frontline Nurses during COVID-19 Pandemic

\begin{tabular}{|c|c|c|c|c|c|c|}
\hline \multirow[b]{2}{*}{ Variables } & \multicolumn{3}{|c|}{ Emotional exhaustion } & \multirow[b]{2}{*}{ Chi-square } & \multirow[b]{2}{*}{$d f$} & \multirow[b]{2}{*}{$p$ value } \\
\hline & Low & Moderate & High & & & \\
\hline \multicolumn{7}{|l|}{ Age } \\
\hline$<30$ & $8(6.7 \%)$ & $30(25 \%)$ & $40(33.33)$ & 1.837 & 4 & 0.766 \\
\hline $31-40$ & $2(1.67 \%)$ & $14(11.67)$ & $22(18.33)$ & & & \\
\hline$>41$ & 0 & $1(0.83 \%)$ & $3(2.5 \%)$ & & & \\
\hline \multicolumn{7}{|l|}{ Gender } \\
\hline Female & $6(5 \%)$ & $34(28.33 \%)$ & $48(40 \%)$ & 1.031 & 2 & 0.597 \\
\hline Male & $4(3.33 \%)$ & $11(9.17 \%)$ & $17(14.17)$ & & & \\
\hline \multicolumn{7}{|c|}{ Fear of infecting family members } \\
\hline Yes & $6(5 \%)$ & $37(27.5 \%)$ & $60(50 \%)$ & $8.212^{*}$ & 2 & 0.016 \\
\hline No & $4(3.33 \%)$ & $8(6.67 \%)$ & $5(4.17 \%)$ & & & \\
\hline \multicolumn{7}{|c|}{ Confident in self-protection } \\
\hline Yes & $8(6.7 \%)$ & $35(29.17 \%)$ & $37(27.5 \%)$ & $6.077^{*}$ & 2 & 0.048 \\
\hline No & $29(24.17 \%)$ & $10(8.33 \%)$ & $28(23.33 \%)$ & & & \\
\hline \multicolumn{7}{|c|}{ Safety against COVID-19 in the workplace } \\
\hline Safe & $3(2.5 \%)$ & $12(10 \%)$ & $10(8.33 \%)$ & $12.35^{*}$ & 4 & 0.015 \\
\hline Somewhat safe & $6(5 \%)$ & $21(17.5 \%)$ & $20(16.67 \%)$ & & & \\
\hline Unsafe & $1(0.83 \%)$ & $12(10 \%)$ & $35(29.17 \%)$ & & & \\
\hline
\end{tabular}

*Significant at 0.05

Table 7: Level of depersonalization among frontline nurses in an emergency in relation to sociodemographic variables $(n=120)$

\begin{tabular}{|c|c|c|c|c|c|c|}
\hline \multirow[b]{2}{*}{ Variables } & \multicolumn{3}{|c|}{ Depersonalization } & \multirow[b]{2}{*}{ Chi-square } & \multirow[b]{2}{*}{$d f$} & \multirow[b]{2}{*}{$p$ value } \\
\hline & Low & Moderate & High & & & \\
\hline \multicolumn{7}{|l|}{ Age } \\
\hline$<30$ & $4(3.33 \%)$ & $46(38.33 \%)$ & $28(23.33 \%)$ & $9.471^{*}$ & 4 & 0.05 \\
\hline $31-40$ & $2(1.67 \%)$ & $16(13.33 \%)$ & $20(1.67 \%)$ & & & \\
\hline$>41$ & 0 & 0 & $4(3.33 \%)$ & & & \\
\hline \multicolumn{7}{|l|}{ Gender } \\
\hline Female & $5(4.17 \%)$ & 49 (40.83\%) & $34(28.33 \%)$ & 3.017 & 2 & 0.221 \\
\hline Male & $1(0.83 \%)$ & $13(10.83 \%)$ & $18(15 \%)$ & & & \\
\hline \multicolumn{7}{|c|}{ Fear of infecting family members } \\
\hline Yes & $5(4.17 \%)$ & $53(44.17 \%)$ & $45(37.5 \%)$ & 0.058 & 2 & 0.97 \\
\hline No & $1(0.83 \%)$ & $9(7.5 \%)$ & $7(5.83 \%)$ & & & \\
\hline \multicolumn{7}{|c|}{ Confident in self-protection } \\
\hline Yes & $4(3.33 \%)$ & $45(37.5 \%)$ & $31(25.83 \%)$ & 2.139 & 2 & 0.343 \\
\hline No & $2(1.67 \%)$ & $17(14.17 \%)$ & $21(17.5 \%)$ & & & \\
\hline \multicolumn{7}{|c|}{ Safety against COVID-19 in the workplace } \\
\hline Safe & $2(1.67 \%)$ & $13(10.83 \%)$ & $10(8.33 \%)$ & & & \\
\hline Somewhat safe & $4(3.33 \%)$ & $25(20.83 \%)$ & $18(15 \%)$ & 2.79 & 4 & 0.59 \\
\hline Unsafe & 0 & $24(20 \%)$ & $24(20 \%)$ & & & \\
\hline
\end{tabular}

*Significant at 0.05

The fear of infection to self and family resulted in the frontliners more susceptible to anxiety and stress during the pandemic. Increased patient physical workloads lead to severe burnout in the form of emotional exhaustion, depersonalization, and reduced personal accomplishment. In the present study, frontline nurses in emergency expressed a moderate to a high level of burnout in emotional exhaustion $(29.13 \pm 10.30)$ and depersonalization $(12.90 \pm 4.67)$ and burnout is less affected in the area of personal accomplishment $(37.68 \pm 5.17)$. Similar results were echoed in a study conducted among Mexican nurses, where burnout was high in dimensions of emotional exhaustion and depersonalization and it was low in personal competence. ${ }^{16}$ The study conducted in Wuhan in the early outbreak of COVID-19 revealed a higher level of burnout among frontline nurses with $41.5,27.6$, and $38.3 \%$ of burnout in emotional exhaustion, depersonalization, and personal accomplishment, indicating a high prevalence of burnout among frontline nurses. ${ }^{17}$ Another study reported more severe degrees of all measurements of mental health outcomes among nurses exposed to COVID-19 patients. ${ }^{18}$

The respondents in this study had a moderate to a high level of resilience with an average total score of 77.77 (SD = 12.41) scoring higher for resilience for nurses as compared to other 
Table 8: Level of personal accomplishment among frontline nurses in the emergency with demographic variables $(n=120)$

\begin{tabular}{|c|c|c|c|c|c|c|}
\hline \multirow[b]{2}{*}{ Variables } & \multicolumn{3}{|c|}{ Personal accomplishment } & \multirow[b]{2}{*}{ Chi-square } & \multirow[b]{2}{*}{$d f$} & \multirow[b]{2}{*}{$p$ value } \\
\hline & Low & Moderate & High & & & \\
\hline \multicolumn{7}{|l|}{ Age } \\
\hline$<30$ & $37(30.83 \%)$ & $30(25 \%)$ & $11(9.17 \%)$ & 7.77 & 4 & 0.100 \\
\hline $31-40$ & $17(14.17 \%)$ & 19 (15.83\%) & $2(1.67 \%)$ & & & \\
\hline$>41$ & $1(0.83 \%)$ & $1(0.83 \%)$ & $2(1.67 \%)$ & & & \\
\hline \multicolumn{7}{|l|}{ Gender } \\
\hline Female & $40(33.33 \%)$ & $33(27.5 \%)$ & $15(12.5 \%)$ & $6.840^{*}$ & 2 & 0.03 \\
\hline Male & $15(12.5 \%)$ & $17(14.17 \%)$ & 0 & & & \\
\hline \multicolumn{7}{|c|}{ Number of members in the household } \\
\hline Alone & $7(5.83 \%)$ & $4(3.33 \%)$ & 0 & $9.335^{*}$ & 4 & 0.05 \\
\hline $2-5$ & $42(35 \%)$ & $34(28.33 \%)$ & $15(12.5 \%)$ & & & \\
\hline$>6$ & $6(5 \%)$ & $12(10 \%)$ & 0 & & & \\
\hline \multicolumn{7}{|c|}{ Fear of infecting family members } \\
\hline Yes & $46(38.33 \%)$ & $43(35.83 \%)$ & $14(11.67 \%)$ & 0.913 & 2 & 0.633 \\
\hline No & $9(7.5 \%)$ & $7(5.83 \%)$ & $1(0.83 \%)$ & & & \\
\hline \multicolumn{7}{|c|}{ Safety against COVID-19 in the workplace } \\
\hline Safe & $13(10.83 \%)$ & $11(9.17 \%)$ & $1(0.83 \%)$ & & & \\
\hline Somewhat safe & $22(18.33 \%)$ & $19(15.83 \%)$ & $6(5 \%)$ & 2.56 & 4 & 0.63 \\
\hline Unsafe & $20(16.67 \%)$ & $20(16.67 \%)$ & $8(6.67 \%)$ & & & \\
\hline
\end{tabular}

*Significant at 0.05

Table 9: Level of resilience among the frontline nurses with demographic variables $(n=120)$

\begin{tabular}{|c|c|c|c|c|c|c|}
\hline \multirow[b]{2}{*}{ Variables } & \multicolumn{3}{|c|}{ Resilience } & \multirow[b]{2}{*}{ Chi-square } & \multirow[b]{2}{*}{$d f$} & \multirow[b]{2}{*}{$p$ value } \\
\hline & Low & Moderate & High & & & \\
\hline \multicolumn{7}{|l|}{ Age } \\
\hline$<30$ & $12(10 \%)$ & $30(25 \%)$ & $36(30 \%)$ & 0.587 & 4 & 0.965 \\
\hline $31-40$ & $6(5 \%)$ & $13(10.83 \%)$ & $19(15.83 \%)$ & & & \\
\hline$>41$ & $1(0.83 \%)$ & $1(0.83 \%)$ & $2(1.67 \%)$ & & & \\
\hline \multicolumn{7}{|l|}{ Gender } \\
\hline Female & $15(12.5 \%)$ & $31(25.83 \%)$ & $42(35 \%)$ & 0.496 & 2 & 0.780 \\
\hline Male & $4(3.33 \%)$ & $13(10.83 \%)$ & $15(12.5 \%)$ & & & \\
\hline \multicolumn{7}{|c|}{ Fear of infecting family members } \\
\hline Yes & $17(14.17 \%)$ & $39(32.5 \%)$ & 47 (39.17\%) & 1.026 & 2 & 0.599 \\
\hline No & $2(1.67 \%)$ & $5(4.17 \%)$ & $10(8.33 \%)$ & & & \\
\hline \multicolumn{7}{|c|}{ Confident in self-protection } \\
\hline Yes & $13(10.83 \%)$ & $27(22.5 \%)$ & $40(33.33 \%)$ & 0.899 & 2 & 0.638 \\
\hline No & $6(1.67 \%)$ & $17(14.17 \%)$ & $17(14.17 \%)$ & & & \\
\hline \multicolumn{7}{|c|}{ Contact with positive COVID-19 patient without protection } \\
\hline Yes & $10(8.33 \%)$ & $28(23.33 \%)$ & $48(40 \%)$ & $9.205^{* *}$ & 2 & 0.010 \\
\hline No & $9(7.5 \%)$ & $16(13.33 \%)$ & $9(7.5 \%)$ & & & \\
\hline \multicolumn{7}{|c|}{ Perception of safety against COVID-19 in the workplace } \\
\hline Safe & $1(0.83 \%)$ & $9(7.5 \%)$ & $15(12.5 \%)$ & $5.130^{*}$ & 4 & 0.0274 \\
\hline Somewhat safe & $7(5.83 \%)$ & $19(15.83 \%)$ & $21(17.5 \%)$ & & & \\
\hline Unsafe & $11(9.16 \%)$ & $16(13.33 \%)$ & $21(17.5 \%)$ & & & \\
\hline
\end{tabular}

*Significant at 0.05

**Significant at 0.01

published studies. ${ }^{19-21}$ For example, a study conducted among 1,061 nurses in Hunan Province China showed a moderate level of resilience, ${ }^{19}$ and a similar result was echoed in Australia also, a moderate level of resilience with a mean score of 70.02. ${ }^{20}$ Another study conducted among UK doctors in 2018 showed a mean CD
RISC score of 65 (SD 12.4); this is below average among the UK population. ${ }^{22}$

Two metrics of burnout, emotional exhaustion, and reduced personal accomplishment had significant negative correlations with the total score of resilience. The observed relationship between the 
variables is consistent with previous studies, where the correlation was weak, ${ }^{20,21}$ but a study conducted by Rushton et al. expressed that the association between burnout and resilience was strong. ${ }^{23}$ Many other studies supported a negative correlation between workrelated burnout among nurses and their resiliency. ${ }^{24,25}$ The result of the present study is supported by research conducted among the different populations in India. ${ }^{26-28}$ These findings proved a high level of resilience helps to manage stress and positively deals with challenges in life and decision-making. The studies substantiate that psychological resilience is a complex phenomenon. Many studies reflect a significant correlation between resilience and psychological well-being. Higher resilience results in enhanced autonomy, personal growth, development optimism, and purpose in life. ${ }^{29,30}$ As demonstrated in these studies, resilience appears to be a protective factor for burnout among nurses. So, it is clear that resilience is really what is essential for nurses to fight against stress, exhaustion, and frustrations in the workplace. Previous researches substantially proved that improving resilience causes increased job satisfaction among nurses, ameliorate nursing turnover internationally. ${ }^{30}$

Therefore, nurse managers in India must take necessary initiatives' earliest to mitigate the burnout and stress among nurses by creating a harmonious and healthy working environment to improve nurses' resilience skills and behaviors in response to the heavy workload and emotional overburden of the pandemics.

In the present study, a high level of emotional exhaustion was reported by frontline nurses who had perceived fear of infecting family members, safety against COVID-19 in the workplace, and confidence in self-protection against COVID-19 infection. In contrast, most nurses (62\%) younger than 30 years reported moderate to a high level of depersonalization, and female frontline nurses (33.33\%) expressed a higher personal accomplishment in the present study.

In many previous studies, demographic variables failed to provide inconclusive evidence to consider a risk factor for burnout. No studies are available regarding COVID-19 related factors and burnout among nurses. Some studies found younger age, gender, marital status, workload, and managerial issues were associated with burnout among nurses. ${ }^{31}$ But the study conducted in Wuhan during the initial period of pandemic revealed an association between emotional exhaustion and gender and education level of the frontline nurses, depersonalization associated with age, gender, and clinical experience. Personal accomplishments of the subjects were associated with age, marital status, and clinical experience ${ }^{17}$. Nurses working in the emergency department are the witnesses of many deaths and poor recovery in patients due to multiple reasons. ${ }^{32-34}$ Many studies had identified different internal and external factors of burnout among nurses. ${ }^{35}$ This study suggests additional researches simultaneously is needed to identify individual factors and environmental factors that create stress among nurses in India.

The present long-lasting nature of pandemic made almost all the health workers in emergencies more panic, and already existing stressors will cause more burnout. Studies suggest that effective interventions reduce nurses' job stress, lighten their burnout, and improve job satisfaction and quality of care. Basic as well as innovative safety approaches in COVID and non-COVID areas are mandatory for the nurses to strengthen the resilience while fighting with this pandemic. ${ }^{36-38}$
The present study provided information at one point in time only. Longitudinal studies are recommended for future studies to capture more in-depth information about the mental health status of frontline nurses. Frontline nurses experienced various mental health challenges, especially burnout and fear, which warrant more attention and support from policymakers. More interventions are necessary to improve frontline nurses' mental health during a pandemic by building self-efficacy and resilience through effective training and infection control classes and providing sufficient social support through online mode.

\section{Strength and Limitations}

Though we got a $100 \%$ response rate with repeated reminders, the credibility of an online survey needs to be considered while inferring the findings. We had included nurses working only in the emergency department, while nurses working in other non-COVID areas also may face burnout in varying degrees. Other healthcare providers working in an emergency who are also potential for burnout were not included in our study. Hence, the generalizability of the present study may be limited to only nurses working in the emergency departments.

\section{CONCLUSION}

The present study identified a moderate to a high level of burnout among nurses in the emergency department, demanding immediate attention. Nurses in the emergency department expressed a moderate to a high level of resilience and resilience demonstrates a significant tool to bring down the burnout and stress among them. These findings point to the importance of developing and implementing interventions that target to reduce burnout and improve resilience among nurses especially in a crisis like a pandemic. This ultimately leads to quality care for patients in emergency departments.

\section{References}

1. World Health Organization. WHO Director General's opening remarks at the media briefing on COVID-19 -March 11, 2020. Available from https://www.who.int/dg/speeches/detail/who-director-generals-opening-remarks-at-the-media-briefing-on-covid-19---11march-2020 cited on 19/07/2020.

2. Bhattacharya A. India sets grim world record with $79 \mathrm{k}$ fresh cases in a day. The Economic Time. 2020 Aug 30: Health world. Available from https://health.economictimes.indiatimes.com/news/industry/indiasets-grim-world-record-with-79k-fresh-cases-in-a-day/77829455.

3. Dey S. $87 \mathrm{k}$ health staff infected with COVID, 473 dead; $74 \%$ cases from six states. The Times of India. 2020 Aug 29. Available from https://timesofindia.indiatimes.com/india/over-87k-health-workersinfected-with-covid-19-573-dead.

4. Ross J. The exacerbation of burnout during COVID 19: A major concern for nurse safety. Journal of Peri Anesthesia Nursing 2020;35(4):439-440. DOI: 10.1016/j.jopan.2020.04.001[internet; cited on 27/08/202] available from https://www.jopan.org/article/S10899472(20)30111-8/pdf.

5. Salvagioni DAJ, Melanda FN, Mesas AE, González AD, Gabani FL, Andrade SM. Physical, psychological and occupational consequences of job burnout: a systematic review of prospective studies. PLoS ONE 2017;12(10):e0185781. DOI: 10.1371/journal.pone.0185781.

6. US Department of Veterans Affairs. Managing healthcare workers' stress associated with the COVID-19 virus outbreak. PTSD: National Center for PTSD. 2020. Available at: https://www.ptsd.va.gov/covid/ COVID_healthcare_workers.asp. Accessed April 4, 2020. 
7. Menon V, Padhy SK, Pattnaik JI. Stigma and aggression against health care workers in India amidst COVID-19 times: possible drivers and mitigation strategies. Indian J Psychol Med 2020;42(4):400-401. DOI: $10.1177 / 0253717620929241$.

8. Jacelon C. The trait and process of resilience. J Adv Nurs 1997;25:123129. DOI: 10.1046/j.1365-2648.1997.1997025123.

9. Jackson D, Firtko A, Edenborough M. Personal resilience as a strategy for surviving and thriving in the face of workplace adversity: a literature review. J Adv Nurs 2007;60(1):1-9. DOI: 10.1111/j.13652648.2007.04412.x.

10. Maslach C, Jackson SE. The measurement of experienced burnout. J Occupat Behav 1981;2(2):99-113. Available from https://onlinelibrary. wiley.com/doi/abs/10.1002/job.4030020205.

11. Connor KM, Davidson JR. Development of a new resilience scale: the Connor-Davidson resilience scale (CD-RISC). Depress Anxiety 2003;18(2):76-82. DOI: 10.1002/da.10113.

12. Woo T, Ho R, Tang A, Tam W. Global prevalence of burnout symptoms among nurses: a systematic review and meta-analysis. J Psychiatr Res 2020;123:9-20. DOI: 10.1016/j.jpsychires.2019.12.015.

13. Poncet MC, Toullic P, Papazian L, Kentish-Barnes N, Timsit J-F, Pochard $F$, et al. Burnout syndrome in critical care nursing staff. Am J Respir Crit Care Med 2007;175(7):698-704. DOI: 10.1164/rccm.200606-806OC.

14. Ahmed AM, Jouhar R, Ahmed N, Adnan S, Aftab M, Zafar SM. Fear and practice modifications among dentists to combat novel coronavirus disease (COVID-19) outbreak. Int J Environ Res Public Health 2020;17(8):2821. DOI: 10.3390/ijerph17082821.

15. Issac A, Stephen S, Jacob J, Vr V, Radhakrishnan RV, Krishnan N, et al. The pandemic league of COVID-19: Korea versus the United States, with lessons for the entire world. J Prev Med Public Health 2020;53(4):228-232. DOI: 10.3961/jpmph.20.166.

16. Cabrera Gutiérrez LS, López Rojas P, Salinas Tovar S, Ochoa Tirado JG, Marín Cotoñieto IA, Haro García L. Burnout syndrome among Mexican hospital nursery staff. Rev Med Inst Mex Seguro Soc 2005;43(1):11-15. Available from https://pubmed.ncbi.nlm.nih.gov/15998476.

17. Deying HU, Kong $\mathrm{Y}$, Qiuying $\mathrm{H}$, Wengang $\mathrm{Li}$, Zhang $\mathrm{X}$, Zhu LX, et al. Frontline nurses' burnout, anxiety, depression, and fear statuses and their association factors during the COVID 19 outbreak in Wuhan, China: a large scale cross-sectional study. E Clin Med 2020;21:48. Available from https://www.thelancet.com/journals/eclinm/article/ PIIS2589-5370(20)30168-1/fulltext.

18. Lai J, Ma S, Wang Y, Cai Z, Hu J, Wei N, et al. Factors associated with mental health outcomes among health care workers exposed to coronavirus disease 2019. JAMA Netw Open 2020;3(3):e203976. DOI: 10.1001/jamanetworkopen.2020.3976.

19. Guo YF, Cross W, Plummer V, Lam L, Luo YH, Zhang JP. Exploring resilience in Chinese nurses: a cross-sectional study. J Nurs Manag 2017;25(3):223-230. DOI: 10.1111/jonm.12457.

20. Hegney DG, Rees CS, Eley R, Osseiran-Moisson R, Francis K. The contribution of individual psychological resilience in determining the professional quality of life of Australia nurses. Front Psychol 2015;6:18. Available from https://www.frontiersin.org/articles/10.3389/ fpsyg.2015.01613/full.

21. Guo Y-F, Luo Y, Lam L, Cross W, Plummer V, Zhang J. Burnout and its association with resilience in nurses: a cross-sectional study. Wiley $\mathrm{J}$ Clin Nurs 2018;27(1-2):441-449. DOI: 10.1111/jocn.13952.

22. McKinley N, McCain RS, Convie L, Clarke M, Dempster M, Campbell WJ, et al. Resilience, burnout and coping mechanisms in UK doctors: a cross-sectional study. BMJ Open 2020;10(1):e031765. DOI: 10.1136/ bmjopen-2019-031765.

23. Rushton $\mathrm{CH}$, Batcheller J, Schroeder K, Donohue P. Burnout and resilience among nurses practicing in high-intensity settings. Am J Crit Care 2015;24(5):412-420. DOI: 10.4037/ajcc2015291.
24. Hegney DG, Rees CS, Robert E, Rebecca OM, Karen F. The contribution of individual psychological resilience in determining the professional quality of life of Australian nurses. Front Psychol 2015;7:1613. Available from https://www.frontiersin.org/article/10.3389/fpsyg.2015. 01613.

25. Mealer M, Conrad D, Evans J, Jooste K, Solyntjes J, Rothbaum B, et al. Feasibility and acceptability of a resilience training program for intensive care unit nurses. Am J Crit Care 2014;23(6):e97-e105. DOI: 10.4037/ajcc2014747.

26. Shalini S, Kumar R. Resilience, psychological well-being and coping strategies in medical students. Indian J Psy Nsg 2019;16:29-37. Available from: http://www.ijpn.in/text.asp?2019/16/2/92/ 276346.

27. Sagone E, Caroli ME. A correlational study on dispositional resilience, psychological well-being, and coping strategies in university students. Am J Educ Res 2014;2(7):463-471. DOI: 10.12691/ education-2-7-5.

28. Somaiya M, Kolpakwar S, Faye A, Kamath R. Study of mechanism of coping, resilience and quality of life in medical undergraduates. Indian J Soc Psychiatry 2015;31(1):19-28. DOI: 10.4103/0971-9962.161995Available from http://www.indjsp.org/ text.asp?2015/31/1/19/161995.

29. Beasley M, Thompson T, Davidson J. Resilience in response to life stress: the effect of coping style and cognitive hardiness. J Personal Individ Differen 2003;34(77):77-95. DOI: 10.1016/S01918869(02)00027-2.

30. Hart PL, Brannan JD, De Chesnay M. Resilience in nurses: an integrative review. J Nurs Manag 2014;22(6):720-734. DOI: 10.1111/j.13652834.2012.01485.

31. Kesarwani V, Husaain ZG, George J. Prevalence and factors associated with burnout among healthcare professionals in India: a systematic review and meta-analysis. Indian J Psychol Med 2020;42(2):108-115. DOI: 10.4103/IJPSYM.IJPSYM_387_19.

32. Dhandapani SS, Manju D, Mahapatra AK. The economic divide in outcome following severe head injury. Asian J Neurosurg 2012;7(1):17. DOI: 10.4103/1793-5482.95690.

33. Dhandapani M, Gupta S, Mohanty M, Gupta SK, Dhandapani S. Prevalence and trends in the neuropsychological burden of patients having intracranial tumors with respect to neurosurgical intervention. Ann Neuroscien 2017;24(2):105-110. DOI: 10.1159/ 000475899.

34. Dhandapani M, Gupta S, Mohanty M, Gupta SK, Dhandapani S. Trends in cognitive dysfunction following surgery for intracranial tumors. Surgical neurology international. 2016;7(Suppl 7):S190. DOI: 10.4103/2152-7806.179229.

35. García-Izquierdo M, Ríos-Rísquez MI. The relationship between psychosocial job stress and burnout in emergency departments: an exploratory study. Nurs Outlook 2012;60(5):322-329. DOI: 10.1016/j. outlook.2012.02.002.

36. Thakur D, Dhandapani M, Ghai S, Mohanty M, Dhandapani S. Intracranial tumors: a nurse-led intervention for educating and supporting patients and their caregivers. Clin J Oncol Nurs 2019;23(3). DOI: 10.1188/19.CJON.315-323.

37. Sahoo SK, Dhandapani S, Singh A. Covid 19: changing patterns among neurosurgical patients of North India, efficacy of repeated testing and patient prevalence. Neurosurg Focus 2020;49(6):[In print].

38. Dhandapani M, Kaur S, Das K, Guru RR, Biswal M, Mahajan P, et al. Enhancing the safety of frontline healthcare workers during coronavirus disease: a novel real time remote audiovisual aided doffing approach. Infectious Disease 2020. 1-3. DOI: 10.1080/23744 235.2020.1836390[In print]. 